\title{
DESTINY OF CHURCH SLAVONIC LANGUAGE HERITAGE IN MODERN RUSSIAN SPEECH CULTURE
}

\author{
Aleksandr P. Skovorodnikov \\ Siberian Federal University, Krasnoyarsk, Russian Federation
}

\begin{abstract}
This article reviews a situation caused by such reasons as persecutions on Russian Orthodox Church in the 20th century, withdrawal of religious texts from school and high school education (first of all, Bibles), which led to the loss of Slavic church linguistic heritage by the Russian and Russian-speaking society. In practice it extremely impoverished the stylistic opportunities of the modern Russian literary language. It turns out that this loss is especially evident in the field of phraseology, in its broad sense, and lexis that defines ethical notions and concepts expressing the world of emotions. On the example of a number of poetic and prosaic texts of the Russian literature of the 19-20th centuries, the author shows that, without the knowledge of basics of the Slavic church language and Bible texts (Old and New Testament), a full perception of Russian classical literary works of the 1920th centuries is not possible. It is asserted that many lexical and phraseological units of the Slavic church language have conceptual, ethical, and esthetical value for the contemporary Russian literary language, and that their "reanimation" is possible if programs of school and high school education will include the study of the Bible as the literary work possessing the major art and ethical importance.
\end{abstract}

Key words: Slavic church language, modern Russian literary language, Bible, language preservation, language development.

УДК 811.163 .1

Дата поступления статьи: 29.08.2016

ББК 81.416 .1

Дата принятия статьи: 04.10.2016

\section{СУДЬБА ЦЕРКОВНОСЛАВЯНСКОГО ЯЗЫКОВОГО НАСЛЕДИЯ В СОВРЕМЕННОЙ РУССКОЙ РЕЧЕВОЙ КУЛЬТУРЕ}

\author{
Александр Петрович Сковородников \\ Сибирский федеральный университет, г. Красноярск, Российская Федерация
}

Аннотация. В статье рассматривается ситуация, обусловленная такими причинами, как гонения на Русскую православную церковь в ХХ в., изъятие из школьного и вузовского образования религиозных текстов (и прежде всего Библии), приведшая к утрате церковнославянского языкового наследия русским и русскоязычным социумом, что на практике чрезвычайно обеднило стилистические возможности современного русского литературного языка. Выявлено, что эта утрата особенно заметна в области фразеологии в широком ее понимании, а также лексики, обозначающей этические понятия и понятия, связанные с миром эмоций. На примере ряда поэтических и прозаических текстов русской литературы XIX-XX вв. показано, что без знания основ церковнославянского языка и текстов Библии (Старого и Нового Заветов) невозможно полноценное восприятие произведений русской классической литературы XIX-XX веков. Утверждается, что многие лексические и фразеологические единицы церковнославянского языка имеют понятийную, этичес- 
кую и эстетическую ценность для современного русского литературного языка и что их «реанимация» возможна, если в программы школьного и вузовского образования будет включено с соответствующим языковым сопровождением изучение Библии как произведения литературы, обладающего большой художественной и этической значимостью.

Ключевые слова: церковнославянский язык, современный русский литературный язык, Библия, сбережение языка, развитие языка.

Скажите сразу, не думав, что сказал Вольтер дорогого человеку на все дни жизни в истории его? Не придумаете, не бросится в ум. А Христос: «Блаженны изгнанные правды ради». Не просто «они хорошо делают», или «нужно любить правду», «нужно за правду и потерпеть», - а иначе: «Блаженны изгнанные за правду, ибо их есть царство небесное». Как изваяно. И стоит 1900 лет. И простоит еще 1900 лет. > .. > Евангелие бессрочно. А все другое срочно - вот в чем дело.

В.В. Розанов

Влечет меня старинный слог. Есть обаянье в древней речи. Она бывает наших слов и современнее и резче. Белла Ахмадулина

\section{1}

Проблема церковнославянского языкового наследия приобретает в наше время особую остроту в связи с заметным снижением речевой культуры россиян, попытками заменить церковнославянский язык как богослужебный современным русским языком, продолжающимся многие годы недопущением изучения этого языка в школе, а также в связи с развернутой за рубежом (а отчасти и в нашей стране) информационно-психологической войной против русского языка и русской цивилизации в целом. В этой ситуации важно понять непреходящую позитивную роль церковнославянского компонента в развитии русского литературного языка и речевой культуры нашего народа. Попытаемся показать это на конкретных примерах.

2

Начнем с наиболее наглядного - с проблемы фразеологии в широком ее понимании.
Выдающийся русский философ А.Ф. Лосев придавал большое значение в культуре русского языка устойчивым библейским оборотам: фразеологизмам, афоризмам, крылатым словам и т. п. В статье «Русская философия» он пишет: «Рассудок создает только схемы. Живую связь бытия и его скрытую сущность нельзя постигнуть с их помощью. Только в образах можно достичь истинного познания». Он обращает наше внимание на Библию как на важнейший источник таких образов и символов [10, с. 218-219].

Посмотрим, как владеет этими символами наше молодое поколение, окончившее полную среднюю школу. Мы провели пилотажный эксперимент со студентами первого курса гуманитарных институтов Сибирского федерального университета (102 участника в возрасте 17-20 лет), которым был дан список из 20 библейских фразеологизмов: петь аллилуйю, аредовы веки, взыскуюшие града, глас вопиющего в пустьне, каинова печать, альфа и омега, петь Лазаря, бесплодная смоковница, блаженны миротвориьы, блудница вавилонская, вавилонский плач, вавилонское столпотворение, бросать камень, валаамова ослица, ветхий Адам (ветхий человек), вложить персты в язвы, выпить чашу до дна, идти на Голгофу, гробы повапленные, блудный сын - и предложено составить с каждым фразеологизмом осмысленное высказывание (предложение). В результате было обнаружено, что только единицы более или менее справились с этим заданием. Фразеологическая компетенция испытуемых была оценена по пятибалльной системе в 0,17 балла (подробнее см.: [13]).

С результатом такого эксперимента соотносимы показания фразеологических словарей русского языка, например, «Энциклопедического словаря библейских фразеологизмов» К.М. Дубровиной. Автор этого словаря справедливо замечает, что «судьба библейской 
фразеологии русского языка довольно драматична. В православно-христианской России изучение Закона Божьего было обязательным во всех русскоязычных учебных заведениях. Поэтому не только высокообразованные, но и просто грамотные люди (например, учившиеся в сельских приходских школах) хорошо знали многие библейские притчи, изречения, афоризмы. Русская интеллигенция была буквально “пропитана" библеизмами, широкое распространение которых в русском языке может быть подтверждено многочисленными примерами из художественных, публицистических и эпистолярных произведений.

Будучи весьма распространенной во всех сферах русской речи до 1917 г., библейская фразеология значительно сократилась в объеме и утратила былую употребительность за годы советской власти, когда Библия находилась под запретом. <..> Естественно, что подавляющее большинство людей, родившихся и живших в советскую эпоху и получивших атеистическое воспитание и образование, не было знакомо с книгами Священного Писания» [5, с. 7-8].

Драматизм ситуации еще и в том, что в так называемое постсоветское время Священное Писание так и не допущено в школу не только в виде Закона Божьего, но и в качестве компонента светского филологического образования хотя бы рамках программ по изучению русского языка и литературы. Поэтому неудивительно, что в языковом сознании нескольких поколений большей части нашего народа библейский компонент отсутствует.

Вернемся к показаниям словаря К.М. Дубровиной. Из 538 фразеологических единиц устаревшими признаны 119. Все они иллюстрированы примерами из художественной литературы и публицистики. Для большей показательности мы взяли только те фразеологизмы с пометой «устар.», которые снабжены тремя и более речевыми иллюстрациями из русской художественной литературы и публицистики (в том числе - современной). Таких фразеологизмов 49, например:

Во время о́но [во времена о́ныl]: примеры из произведений В.В. Жукова, В.В. Крестовского, М.Ю. Лермонтова, Д.В. Григоровича, П.И. Мельникова-Печерского, Ю.С. Крымова, Н.С. Лескова, А.П. Чехова (два), Ф.М. Достоевского.
Возвышать [возвысить] голос: примеры из произведений М.Ю. Лермонтова, В.Г. Короленко, Ю.Н. Лебединского, газеты «Сегодня».

Все в руце Божией: примеры из произведений В.Ф. Тендрякова, Ю.П. Германа, В.С. Шефнера, газеты «Правда».

Геенна огненная: примеры из произведений П.И. Мельникова-Печерского (два), А.П. Чехова, И.И. Гарина, Ю.П. Германа, В. Еременко, В. Славянина, А.Н. Островского, газет «Трибуна» и «Правда».

Гроб повапленный [гробы повапленные]: примеры из произведений В.Г. Белинского, Г.И. Успенского, В.И. Ленина, М.Ю. Лермонтова, Н. Карташева, газет «Петербургский Час Пик» и «Итоги».

Египетская работа [египетский труд]: примеры из произведений С.Т. Аксакова, А.А. Марлинского, А.П. Чехова (два), Ф.А. Абрамова.

Как птица небесная [Божия]: примеры из произведений М.Ю. Лермонтова, Д.Н. Мамина-Сибиряка, Н.Д. Телешова, Н.С. Лескова.

Медь звенящая, кимвал бряиающий [звенящий, звучащий]: примеры из произведений В.Г. Белинского, В.А. Жуковского, М.Е. Салтыкова-Щедрина, А.С. Пушкина, Ив. Иванова, В.В. Ерофеева.

Ныне отпушаеши: примеры из произведений М.Е. Салтыкова-Щедрина (три), А.И. Герцена, В.В. Маяковского, В.В. Ерофеева.

Грех тебя [меня, его, ее, нас, вас, их] возьми [побери, дери, подери]: примеры из произведений А.С. Грибоедова, А.Ф. Писемского (два), М.А. Шолохова.

Раб Божий [раба Божья]: примеры из произведений А.С. Пушкина (два), И. Шульженко, М.Е. Салтыкова-Щедрина, П.А. Вяземского, журнала «Огонек».

Хамово отродье [племя]: примеры из произведений А.Ф. Писемского, И.С. Тургенева, А.И. Эртеля, А.П. Чехова, А.С. Грибоедова, К.Г. Паустовского.

Чающие движения водь: примеры из произведений В.Г. Белинского, М.Ю. Лермонтова, А.М. Герцена, М.Е. Салтыкова-Щедрина (два), В.В. Стасова, Д.Н. Мамина-Сибиряка, А.А. Соколова (подробно см. ЭСБФ).

Спорным представляется отнесение к устаревшим фразеологизма Ныне отпущае$u и$, который известен миллионам верующих 
как начало «Песни Симеона Богоприимца», вошедшей в состав молитв всех основных христианских церквей: Ныне отпущаеши раба Твоего, Владыкко, по глаголу Твоему сь миромъ... Важно также отметить, что помету «устар.» в этом словаре получают главным образом фразеологизмы, имеющие в своем составе церковнославянскую лексику и / или грамматические формы, а также то, что в состав устаревших фразеологизмов попали такие прецедентные высказывания, как заповеди блаженства, составляющие суть учения Иисуса Христа: $A$ я говорю вам: не противься злому, но кто ударит тебя в правую щеку твою, обрати к нему и другую; Блаженны миротвориы, ибо они будут наречены сынами Божиими; Блаженны нищие духом, ибо их есть Царство Небесное (Библия, с. 307-308).

Трудно представить, что люди, владеющие полнофункциональной (элитарной) речевой культурой, не знают и не употребляют упомянутых выше фразеологизмов. Скорее всего, помета «устар.» часто (в том числе и в данном случае) является показателем деградации языкового сознания большой (скорее всего - бо́льшей) части русскоязычного социума, а также свидетельством недооценки категории полнофункциональной речевой культуры как ориентира в деле повышения языковой и речевой культуры общества.

Ответа на вопрос, почему такие фразеологизмы считаются устаревшими, в указанном словаре нет. По-видимому, понятие «устаревшей» языковой единицы ориентировано не на высококультурную часть социума, то есть на представителей полнофункциональной речевой культуры, а на носителей ее низших страт, которые, как пишут В.Е. Гольдин и О.Б. Сиротинина, все «в большей или меньшей степени “ущербны” с точки зрения возможностей полноценного и творческого использования языка» [4, c. 414].

Ситуация, подобная вышеописанной, наблюдается и в области лексики, прежде всего книжной, часто восходящей к церковнославянскому языку. В данном контексте весьма интересны наблюдения доктора философских наук Леонида Когана, опубликованные в разгар «перестройки» (1986 г.) и сохраняющие свою значимость в наше время: «Нельзя не пожалеть, что сравнительно редко и не во всей своей масштабности, многомерности употребляются теперь в обиходной и литературной практике наряду с понятиями “дух" и “душа" такие производные от них слова и словосочетания, как душевность, задушевность, одухотворенность, великодушие, прямодушие, совестливость, чистосердечность, непосредственность, искренность, откровенность, сокровенность, беззастенчивость, возвышенность (духовная высота), духовная жажда, окрыленность, душевный покой, душевная глубина, душевный порыв, душевное горение. <..> Реже, чем хотелось бы, встречается ныне и гнездо слов, группирующихся вокруг понятия “добро": доброжелательность, добросердечие, добродушие, добропорядочность, добросовестность, добронравие, добродетель и связанные с ними человеколюбие, милосердие, отзывчивость, участливость, жалость, сострадание, приязнь, признательность, верность, постоянство, деликатность, учтивость, укоризна, стыл (в противоположность бесстыдству), раскаяние, искупление. $<\ldots>\mathrm{He}$ очень, пожалуй, заметное место занимают понятия доброты и в шкале нравственных ценностей, которыми оперируют профессиональные этики-философы. То же относится к родственной группе слов, восходящих к корню "благо": благожелательность, благосклонность, благорасположение, благотворность, благодеяние, благодарность, благородство, благоразумие, благовоспитанность, благопристойность, благоговение и др. Редкое использование этих и других близких им слов-значений не только обедняет наше повседневное общение, но и приглушает, обесцвечивает духовно-душевную палитру, возможности нравственного воспитания и самовоспитания» [7]. Заметим, кстати, что большая часть вышеприведенных слов по происхождению являются церковнославянскими или образованы по церковнославянской модели с использованием соответствующих «строительных элементов».

Критикуя «Словарь эпитетов русского литературного языка» К.С. Горбачевича и 
Е.П. Хабло, писатель Андрей Битов иронично пишет: «Из 28 эпитетов к слову ДОМ устар. - три: отчий, добропорядочный, честный. Причем допропорядочный дом даже больше, чем “устар.”, - он “устар. и шутл.”»; < ...> «Устар. МИР - благодатный, благодетельный, благополучный, блаженный. Устар. МИР - неправедный и святой. РАДОСТЬ устарела: и быстротечная, и забывчивая, и легкокрылая, и лучезарная, и лучистая, и даже нищенская, но и святая. Зато ПЫТКА не устарела никакая - ни дьявольская, ни зверская, ни изуверская, ни инквизиторская, ни лютая, ни средневековая, ни чудовищная. Может потому, что устарело само слово?.. Так к слову СОВЕСТЬ вы не найдете ни одного эпитета, потому что слова этого нет в словаре вообще» [1, с. 114-115].

По-видимому, проблема устаревших слов - своего рода «черная дыра» лингвистической теории и практики, а ссылки на демократизацию речи, звучащие всякий раз, когда обнаруживаются языковые утраты или массовые нарушения литературной нормы, не более чем эвфемизмы, прикрывающие снижение речевой культуры социума.

Деградация языковой личности нашего среднестатистического современника особенно заметна в сфере этических понятий и соответствующей лексики, генетически часто восходящей к церковнославянскому языку, его моделям и элементам. Так, в экспресс-опросе 40 студентов 1-го курса был предложен список из 60 книжных слов-существительных, обозначающих душевные качества человека, для выявления степени их употребительности.

В результате оказалось, что наибольшее затруднение для испытуемых (треть и более информантов) составили слова, выражающие абстрактные этические понятия и в большинстве своем восходящие к церковно-религиозным текстам: бездуховность, воздержание, греховность, грехопадение, добродетель, духовность, искупление, кротость, моральность, миролюбие, незлобивость, нестяжание, покаяние, праведность, святость, сердечность, служение, совестливость, созидание, самоотречение, иеломудрие, этичность.

Но если «уходят» слова, то уходят и выражаемые ими понятия, а следовательно «съе- живается» и этическая часть сознания тех, для кого эти слова перестали существовать. Довольно большой список таких слов, вошедших в русский литературный язык под влиянием славянского «Апостола» и «Откровения» Иоанна Богослова, дан в [3, с. 170-173].

\section{4}

Значение евангельских текстов в лексико-фразеологическом обогащении русского литературного языка можно увидеть, обратившись к тем высказываниям, словосочетаниям и именам, которые стали прецедентными. Только в одном Евангелии от Матфея мы находим: глас вопиющего в пустыне; ловцы человеков; нищие духом; алчущие и жаждущие правды и т. д. - всего 72 единицы.

Все эти обороты, хотя и нечасто, встречаются в современных высококачественных публицистических текстах, в том числе и в трансформированном виде. Однако среднестатистический читатель по незнанию своему их не замечает и, естественно, не употребляет в своей речи. Только представим себе, какой ущерб нанесен речевой культуре и языковому сознанию нашего народа, если из этого сознания выпала хотя бы половина выявленных прецедентных текстов, в чем вряд ли можно сомневаться. И как важно реанимировать в сознании носителей русского языка это языковое богатство!

Многие тексты нашей классики не могут быть полноценно восприняты без знания текста Евангелия. Приведу несколько примеров (некоторые из которых взяты из публикаций М.М. Дунаева [6]). В стихотворении А.С. Пушкина «Странник» есть такие строки: Иди ж, он продолжал, - держись сего ты света; / Пусть будет он тебе единственная мета, / Пока ты тесных врат спасенья не достиг... (здесь и далее выделено мною. $-A$. C.). Глубинный смысл этих строк читатель может понять только в том случае, если ему знакомо евангельское: Bходите тесными вратами, потому что широки врата и пространен путь, ведущие к погибели, и многие идут ими; потому что тесны врата $и$ узок путь, ведущие в жизнь, и немногие находят их (Мф. 7, 13-14). Невозможно понять религиозное содержание стихотворения 
А.С. Пушкина «Отцы пустынники...» ${ }^{1}$ без знания семантики использованных в нем церковнославянизмов и текста молитвы Ефрема Сирина «Господи владыко живота моего...», вдохновившей Пушкина. Религиозно-философский пафос пушкинского шедевра «Пророк» не может быть интеллектуально и эмоционально воспринят без понимания значения и ощущения стилистической роли церковнославянской лексики, составляющей основу этого стихотворения.

Без знания Библии трудно понять и стихотворение Ф.И. Тютчева «При посылке Нового Завета», в частности последние две строфы: Но этой веры для немногих / Лишь тем доступна благодать, / Кто в искушеньях жизни строгих, / Как вы, умел, любя, страдать, / Чужие врачевать недуги / Своим страданием умел, / Кто душу положил за други / И до конца все претерпел. Полнота восприятия здесь возможна при адекватном тексту понимании семантики таких слов, как благодать, искушенья, страдать, и знании соответствующих фрагментов Евангелия, получивших статус интертекстуальных, в данном стихотворении представленных парафразами высказываний Иисуса Христа: Hem больше той любви, как если кто положит душу за друзей своих (Ин. 15, 13) и И будете ненавидимы всеми за имя Мое; претерпевший же до кониа спасется (Мф. 10, 22). Православно-нравственное значение слов страдать, страдание можно понять только в контексте Евангелия и ориентированного на него поэтического дискурса. Ср. у Пушкина в стихотворении «Элегия»: Но не хочу, о други, умирать; / Я жить хочу, чтоб мысллить и страдать... «Неожиданный, парадоксальный исход, - замечает по поводу этих строк М.М. Дунаев. - Так может сказать только истинный христианин. И мужественный духом верующий. Обычно люди бегут от страданий. Пушкиным же очищающие душу страдания не отвергаются, но мыслятся как одна из важнейших жизненных ценностей. Давняя пушкинская дихотомия является в прикровенном облике: ум (“чтоб мыслить”) и сердце, душа (“чтоб страдать”)» [6, ч. 1, с. 220].

Без знания церковнославянской сюжетной основы, лексики и фразеологии невозможно полноценно воспринять мысль и чувство та- ких произведений русской словесности, как стихотворение Сергея Есенина «Иорданская голубица», где, кроме самого названия, встречаются такие слова, имена, образы и аллюзии: С дудкой пастушеской в нивах / Бродит апостол Андрей; Мати Пречистая Дева; Все мы, все когда-нибудь / В тех благих селеньях будем; Кто сегодня был любимец - / Завтра нищий человек; Дождиком в нивы златые / Нас посетил Авраам; Буду тебе я молиться, / Славить свою Иордан $;$; стихотворение Осипа Мандельштама, начинающееся строфой: Отравлен хлеб и воздух выпит. / Как трудно раны врачевать! / Иосиф, проданный в Еzипет, / Не мог сильнее тосковать!; стихотворение Бориса Пастернака «Гамлет»: На меня наставлен сумрак ночи / Тысячью биноклей на оси.

/ Если только можнно, Авва Отче, / Чашу эту мимо пронеси; стихотворение Ивана Бунина «Люцифер»: Великий сфинкс, исполненный печали, / Лежал в песках. Израиль, чуждый всем, / Сбирал, рыдая, ржавые скрижали. / Христос покинул жадный Вифлеем; стихотворения Владимира Ходасевича «Путем зерна» и «Слезы Рахили» и стихотворения Анны Ахматовой «Рахиль», «Лотова жена», «Мелхола», основа которых - библейские сюжеты.

То же можно сказать и о прозаических произведениях. Невозможно постигнуть глубину содержания и художественное обаяние таких текстов художественной прозы, в которых описываются православные традиции и поступки православных людей, например, «Лето Господне», «Неупиваемая чаша» Ивана Шмелева; «Афон», «Валаам», «Преподобный Сергий Радонежский» Бориса Зайцева; «Анафема» Александра Куприна; «Однодум», «Соборяне», «Запечатленный ангел», «Очарованный странник» Николая Лескова и др. Перечень произведений русской поэтической и прозаической классики, так или иначе связанной с сюжетами, образами и языком Библии и текстов отцов Церкви, можно продолжать и продолжать.

5

Утрата многих книжных слов, в том числе и прежде всего церковнославянского про- 
исхождения, ведет к деформации стилистической системы русского языка. Профессор В.В. Колесов по этому поводу пишет: «Самая большая беда, обозначившаяся в XX веке, заключается в утрате высокого стиля. История русской культуры требует наличия трех стилей - триипостасность литературного языка обусловлена положением, которое точно отмечено тем же Владимиром Соловьевым: словом высокого стиля мы обращаемся к Богу, среднего - к другому (это профессиональная речь, формирующая норму), низким беседуем с самим собою (в бытовом кругу); исчезновение высокого стиля привело к тому, что вульгарный низкий стиль занял место среднего, традиционно являвшегося источником поступления в литературный язык нормативных элементов системы (средний стиль заместил высокий)» [8, с. 151].

Аргументом в пользу церковнославянского языка как языка богослужебного, а также сохранения живой связи с ним русского литературного языка служат его высокие эстетические качества. Это можно иллюстрировать простым сравнением текстов Евангелия на церковнославянском языке и текстов Евангелия на современном русском языке. Cp., например: Блаженны алчущие и жаждущие правды, ибо они насытятся (церковнославянский вариант) и Счастливы те, кто жаждет праведности - они будут удовлетворены (вариант на современном русском взят из протестантской «Книги жизни», изданной в 1990 г. обществами «Библия для всех» и «Лайф Паблишер» в сотрудничестве с христианскими церквями в СССР). Церковнославянский текст - развернутая метафора, современный русский текст лишен этой образности. Кроме того, содержание концепта «правда» значительно шире содержания концепта «праведность» (не даром последний не рассматривается в таком капитальном труде, как [14]). В современном русском языке праведность, образуемая от праведный, значит «1. благочестивый, безгрешный, соответствующий религиозным правилам. Праведная жизнь. 2. Основанный на правде (во 2 знач.), справедливый (устар.) П. суд. П. судья [14, c. 714]. Правда же в словаре Ю.С. Степанова (с опорой на словарь В.И. Даля) связывается с понятиями истины и справедливос- $m u$, которые органично соединяются в понятии «правда» (православный императив «жить по Божьей правде») [14, с. 318-320]. Именно такое значение имеет слово правда в вышеприведенной заповеди блаженства.

В сводном тексте четырех Евангелий Библии, изданном обществами «Библия для всех» и «Лайф Паблишер» в сотрудничестве с христианскими церквями в СССР, текст молитвы «Отче наш» передается на современном русском языке так:

Наш небесный Отец, пусть же прославится имя Твое! / Пусть наступит царство Твое и свершится воля Твоя / как на небе, так и на земле. / Дай нам сегодня хлеб на пропитание. / Прости нам долги наши, как и мы прощаем должникам нашим. / Удержи нас от искушений, и избавь нас от зла. / Тебе принадлежит царство, сила и слава навеки. Аминь.

Ср. этот текст с русифицированным переводом того же церковнославянского текста в Евангелии, изданном по благословению Святейшего Правительствующего Синода в Санкт-Петербурге в 1912 г. (Св. Ев., с. 22) и тождественным ему текстом Евангелия в русском переводе 1991 г.:

9. Отче нашъ, сущій на небесахъ! да святится имя Твое; / 10. да пріидеть царствіе Твое; да будеть воля Твоя и на земле, какъ на небе; / 11. хлебъ нашъ насущный дай намъ на сей день; / 12. и прости намъ долги наши, какъ и мы прощаемъ должникамъ нашимъ; / 13. и не введи нась в искушеніе, но избавь насъ от лукавого; ибо Твое есть Царство и сила и слава во веки. Аминь (Библия, с. 309).

Стилистически эти тексты существенно отличаются. Сопоставим попарно соответствуюшие слова и обороты: пусть прославится - да святится; пусть наступит и свершится - да приидет, да будет; хлеб на пропитание - хлеб наш насущный; сегодня на сей день; удержи нас от искушений не введи нас в искушение; избавь нас от зла - избавь нас от лукавого; Тебе принадлежит царство - ибо Твое есть Царство. Нетрудно заметить, что некоторая архаизация, достигаемая во втором тексте за счет сохранения церковнославянских слов и оборотов, вместе с инверсией (ср.: наш небесный Отеи и Отче наш, сущий на небесах; дай 
нам сегодня хлеб и хлеб наш насущный дай) способствуют высоте стиля, молитвенному пафосу, чего нет в первом тексте. Причем второй текст не менее понятен, чем первый, но в первом тексте утрачен фразеологизм от лукавого, широко используемый в современном русском литературном языке. Стилистическое и семантическое различие этих текстов хорошо прослеживается в сопоставлении выражений и оборотов: пусть же прославится имя Твое (в первом тексте) и да святится имя Твое (во втором). Профессор А.Ч. Козаржевский по этому поводу замечает: «Помилуйте, “Да святится" - это одно, “Да прославится" - совсем другое. "Святится" - это проявление нашей любви. Вообще, “Отче наш" - это средоточие всех добродетелей. "Иже еси на небесех" - вера, “Да святится имя Твое" - любовь, “Да приидет царствие Твое” - надежда, “Да будет воля твоя" - премудрость, "Хлеб наш насущный даждь нам днесь" - воздержание, "Не введи нас во искушение" - твердость» [2, с. 235-236].

Обратим внимание на то, что професcop А.Ч. Козаржевский цитирует Евангелие на церковнославянском языке, текст которого, данный в русской транскрипции, в целом совершенно понятен русскому человеку (см.: Св. Ев., с. 22).

Высокая эстетика церковнославянского языка прослеживается в сопоставлении молитвы Ефрема Сирина и поэтической парафразы этой молитвы у А.С. Пушкина:

Молитва Ефрема Сирина:

Господи и Владыко живота моего, дух праздности, уныния, любоначалия и празднословия не даждь ми. Дух же целомудрия, смиренномудрия, терпения и любве даруй ми, рабу Твоему. Ей, Господи, Царю, даруй ми зрети моя прегрешения и не осуждати брата моего, яко благословен еси во веки веков. Аминь (Молитвослов, с. 287-288).

\footnotetext{
А.С. Пушкин. «Отцы пустынники...»:$$
<\ldots>
$$

Владыко дней моих! дух праздности унылой, Любоначалия, змеи сокрытой сей, И празднословия не дай душе моей. Но дай мне зреть мои, о Боже, прегрешенья, Да брат мой от меня не примет осужденья, И дух смирения, терпения, любви

И целомудрия мне в сердце оживи.
}

Конечно, сопоставляя эти тексты с точки зрения эстетического воздействия, мы вступаем в область субъективных оценок. Поэтому предлагаю читателям самим ответить на вопрос об их эстетической конгениальности.

Текст молитвы Ефрема Сирина, как и текст молитвы «Отче наш», может служить доказательством того, что для овладения лексическими и грамматическими особенностями церковнославянского языка нужно очень немного усилий, и, таким образом, у сторонников перевода богослужебных текстов на современный русский язык основной аргумент оказывается несостоятельным.

Убедительные аргументы в пользу сохранения церковнославянского языка как богослужебного приводятся в книге дьякона Андрея Кураева [9, с. 122.], а также в материалах дискуссии по рассматриваемой проблеме, см., например: URL: http://www.hram-ks.ru/tsslav9.shtml (дата обращения: 13.05.2016); URL: http://www.hram-ks.ru/Karelin1.shtml (дата обращения: 13.05.2016); URL: http://www.hram-ks.ru/ Alex pust.shtml (дата обращения: 13.05.2016); URL: http://www.hram-ks.ru/ts-slav8.shtml (дата обращения: 13.05.2016); URL: http://www.hramks.ru/ts-slav7.shtml (дата обращения: 13.05.2016); URL: http://www.hram-ks.ru/tsslav6.shtml (дата обращения: 13.05.2016) и др. статьи на сайтах «Православие.py» (http:// www.pravoslavie.ru) и «Богослов. py» (http:// www.bogoslov.ru).

\section{6}

В связи со сказанным отдельного рассмотрения заслуживает возможность «реанимации» в качестве функционирующих единиц слов и фразеологизмов церковнославянского языка, особенно в сфере этических понятий.

Значительные возможности для заполнения лексических лакун, в том числе и прежде всего этического порядка, может предоставить церковнославянская лексика. Приведу несколько примеров из «Полного церковнославянского словаря» Григория Дьяченко $(\text { ПСС })^{2}$ : «Благолюбивый - любящий добро»; «грехолюбивый - поползновенный ко грехам»; «грехоочистительный - очищающий от грехов»; «душегубительный - погубляю- 
щий душу»; «душепитательный - питающий душу»; «душерастлитель - растлевающий душу, соблазнитель»; «лжебрат - тот, который по наружности кажется друг, а внутри ненавистник»; «тайновидеи - открывающий тайны»; «терпеливомудрый - сопровождаемый мудрым терпением», «здравоносный подающий, восстанавливающий здоровье», «злотворный-наносящий зло, причиняющий неприятности» и др.

Церковнославянским словам, выражающим нужные понятия, в словарях современного русского языка часто либо нет заменителей, либо есть близкие по значению слова (в том числе синонимы), от которых церковнославянские слова отличаются каким-либо оттенком значения или стилистической коннотацией. Например: «христоподобный подобный жизнью или подвигами Иисусу Христу», «цветный-имеющий яркий цвет», «саморучно - собственной рукой» (руками), «равноименованный - нарицающийся одним именем с другим»; «достоподражсаемый - достойный подражания»; «самочинник - тот, который поступает по своевольству» (при наличии в словарях современного русского языка слов «самочинный», «самочинность», «самочинствовать», «самочинство»); «прекословныи - любящий возражать» (при наличии в словарях глагола «прекословить»); «женонравныц - имеющий женский нрав» (не равноценно слову «женоподобный», которое характеризует не нрав, а внешность); «ратобореи - ратник, подвижник» (по сравнению со словом «ратник» «ратоборец» - слово высокого стиля с семантическим оттенком героизма); «хитрословесный - искусно говорящий, красноречивый» (для современного языкового сознания будет иметь семантический оттенок лукавства); «запинательный - служащий препятствием, помехой» (по сравнению с такими словами, как «мешающий», «препятствующий», обладает качеством образности, изобразительности); «чревобесие - объядение, обжорство», как и «ядоглаголивый - злоречивый» (см. ПЦСС), пополняют соответствующие градационно-синонимические ряды компонентами, обладающими большей интенсивностью отрицательной оценки. Достаточно очевидно, что приведенные слова (или хотя бы некото- рые из них) способны обогатить семантически и / или стилистически лексику современного русского языка.

Тезис о языковой «реанимации» утраченных слов и фразеологизмов, сохраняющих актуальность для нашего времени, находит косвенную поддержку, опосредованную философско-религиозной идеей труда воскрешения, в философии Н.Ф. Федорова, который христианство понимает «как религию дела, призывающую не только к духовной, нравственной, социальной, но и к онтологической активности (выделено мной. - A. C.). Научное знание и преобразовательное действие включаются в "работу спасения", служа преодолению смерти» [11]. Н.Ф. Федоров, понимая воскрешение как «обращение прошедшего в настоящее, в действительное» [16, с. 58], писал: «Задача сынов человеческих - восстановление жизни, а не одно устранение смерти» (курсив Федорова. A. C.) $[16$, с. 272$]$. Опору нашим рассуждениям находим также у немецкого философа О. Розенштока-Хюсси: «Названные некогда имена - это та часть нашего будущего, на которую указали наши предшественники. Наше прошлое является наполовину прахом, а наполовину оно - уже созданная часть нашего будущего» [12, с. 17].

На мой взгляд, «реанимация» актуальной части церковнославянского языкового наследия вполне осуществима. Полагаю, что восстановление древнееврейского классического языка - иврита и почти исчезнувшего чешского литературного языка является тем вдохновляющим примером, который говорит в пользу идеи восстановления в русском литературном языке и речевой практике ценных элементов церковнославянского литературного наследия. Словом, было бы желание, воля и, конечно, соответствующая языковая политика государства, прежде всего - в области образования.

Итак, все вышесказанное наводит на мысль о том, что важной, хотя и не единственной, причиной лексико-фразеологического оскудения речи молодого поколения нашей страны является неудовлетворительный 
уровень преподавания русского языка и литературы в средней и высшей школе (как в количественном, так и в качественном смысле), падение читательской культуры и многолетнее, длящееся на протяжении жизни нескольких поколений исключение из учебного процесса великой книги человечества Библии, и прежде всего Евангелия. Это приводит к тому, что в языковом сознании людей отсутствует большой пласт языковых единиц русского языка, не восполняемый и в семейном речевом общении. Причем из языкового сознания уходят в первую очередь слова редко употребляемые и слова стилистически маркированные, главным образом книжные. Создавшаяся лексико-фразеологическая лакуна в языковом сознании молодежи отчасти объясняет, почему это поколение не читает классическую литературу: язык этой литературы стал для него чужим и малопонятным.

Процесс вымывания из языкового сознания значительной части нации нужных для когниции, одухотворенной жизни и полноценного общения слов, оборотов и соответствующих смыслов - это проблема не только культурноречевая, но и лингвоэкологическая, так как мы имеем дело не только с ущербностью речевой культуры, но и с травмой языка, поскольку происходит омертвление его существенной части и, как следствие, увеличивается разрыв между носителями разных типов речевой культуры и культурой разных поколений в целом, о чем писал русский философ Н.С. Трубецкой: «...всякое молодое поколение должно усваивать, путем подражания старшим, культуру, в которой выросло предшествующее поколение и которую это поколение, в свою очередь, получило от своих предшественников. Для каждого поколения полученная таким путем традиции культура является исходной точкой дальнейших открытий, и это обстоятельство является одним из непременных условий непрерывности и органичности развития культуры» [15, с. 706-707].

Дело русистов-лингвоэкологов - сделать все возможное, чтобы не допустить окончательного языкового и культурного разрыва поколений, языковой и речевой деградации русскоговорящего мира.

\section{ПРИМЕЧАНИЯ}

1 Здесь и далее произведения русских поэтов цитируются по: Национальный корпус русского языка. - Электрон. текстовые дан. - Режим доступа: http://ruscorpora/ru/. - Загл. с экрана.

2 Здесь и далее при цитировании ПЦСС используется упрощенная графика.

\section{СПИСОК ЛИТЕРАТУРЫ}

1. Битов, А. Битва. Первая публикация отдельной книгой / А. Битов. - М. : Arsis Books, 2009. $120 \mathrm{c}$.

2. Богослужебный язык русской церкви. История. Попытки реформации / сост. Н. Каверин. М. : Изд-во Сретенского монастыря, 1999. - 411 с.

3. Верещагин, Е. М. Библеистика для всех / Е. М. Верещагин. - М. : Наука, 2000. - 281 с.

4. Гольдин, В. Е. Речевая культура / В. Е. Гольдин, О. Б. Сиротинина // Русский язык. Энциклопедия / гл. ред. Ю. Н. Караулов. - 2-е изд., перераб. и доп. - М. : Большая Российская энциклопедия : Дрофа, 1997.- С. 413-415.

5. Дубровина, К. М. Предисловие / К. М. Дубровина // Энциклопедический словарь библейских фразеологизмов. - М. : Флинта : Наука, 2010. - С. 4-12.

6. Дунаев, М. М. Православие и русская литература : в 5 ч. / М. М. Дунаев. - М. : Христианская литература, 1996. - Ч. 1. -320 с. ; Ч. 2. -480 с.

7. Коган, Л. «...Душа моя во мне». Об одном аспекте экологии культуры / Л. Коган // Советская культура. - 1986. - 22 нояб.

8. Колесов, В. В. «Жизнь происходит от слова...» / В. В. Колесов. - СПб. : Златоуст, 1999. - 368 с.

9. Кураев, А. (дьякон). Почему православные такие? / дьякон Андрей Кураев. - М. : Подворье Свято-Троицкой Сергиевой Лавры, 2006. -528 с.

10. Лосев, А. Ф. Русская философия / А. Ф. Лосев // Философия. Мифология. Культура. - М. : Политиздат, 1991. - С. 209-236.

11. Новицкая, Ю. Русский космизм / Ю. Новицкая // Завтра. - 2015. - № 38. - Электрон. текстовые дан. - Режим доступа: http://old.zavtra.ru/content/ view/russkij-kosmizm-2/. - Загл. с экрана.

12. Розеншток-Хюсси, О. Бог заставляет нас говорить / О. Розеншток-Хюсси ; сост., пер. с нем. и англ., послесловие и коммент. А. И. Пигалева. - М. : Канон-Плюс, 1997. - 288 с.

13. Сковородников, А. П. К философским основаниям предметной области эколингвистики / А. П. Сковородников // Экология языка и коммуникативная практика. - 2014. - № 2. - С. 140-161.

14. Степанов, Ю. С. Константы. Словарь русской культуры. Опыт исследования / Ю. С. Степа- 
нов. - М. : Школа «Языки русской культуры», 1997. $824 \mathrm{c}$.

15. Трубецкой, Н. С. Европа и человечество / Н. С. Трубецкой // Русский мир : сборник. - М. ; СПб. : Эксмо : Terra Fantastica, 2003. - С. 663-737.

16. Федоров, Н. Ф. Сочинения / Н. Ф. Федоров ; сост., вступ. статья и прим. С. Г. Семеновой. - М. : Раритет, 1994. - 416 c.

\section{ИСТОЧНИКИ И СЛОВАРИ}

Библия - Библия. Книги Священного Писания Ветхого и Нового Завета. Канонические. - М. : Библейские Комиссии «Духовное Просвещение», 1991. - Т. 2. - $621 \mathrm{c}$.

Горбачевич, К. С. Словарь эпитетов русского литературного языка / К. С. Горбачевич, Е. П. Хабло. - Л. : Наука, 1979. - 567 с.

Молитвослов - Молитвослов. - СПб. : Библиополис, 2009. - 320 с.

Национальный корпус русского языка. - Электрон. текстовые дан. - Режим доступа: http:// ruscorpora/ru/. - Загл. с экрана.

ПЦСС - Полный церковно-славянский словарь (с внесеніем в него важнейших древне-русских слов и выраженій). Репр. воспроизведение изд. 1900 г. / сост. Г. Дьяченко. - М. : Посад, 1993. $1120 \mathrm{c}$.

Св. Ев. - Господа нашего Иисуса Христа Святое Евангелие от Матфея, Марка, Луки и Иоанна на славянском и русском языках. - СПб. : Синодальная типография, 1912. - $464 \mathrm{c.}$

ЭСБФ-Дубровина, К. М. Энциклопедический словарь библейских фразеологизмов / К. М. Дубровина. - М. : Флинта : Наука, 2010. - 808 с.

\section{REFERENCES}

1. Bitov A. Bitva. Pervaya publikatsiya otdelnoy knigoy [Fight. First Publication as a Separate Book]. Moscow, Arsis Books Publ., 2009. 120 p.

2. Kaverin N. Bogosluzhebnyy yazyk russkoy tserkvi. Istoriya. Popytki reformatsii [Liturgical Language of the Russian Church. History. Reformation Attempts]. Moscow, Izd-vo Sretenskogo monastyrya, $1999.411 \mathrm{p}$.

3. Vereshchagin E.M. Bibleistika dlya vsekh [Bible Studies for Everyone]. Moscow, Nauka Publ., 2000. $281 \mathrm{p}$.

4. Goldin V.E., Sirotinina O.B. Rechevaya kultura [Speech culture]. Karaulov Yu.N., ed. Russkiy yazyk. Entsiklopediya [Russian Langauge. Encyclopedia]. Moscow, Bolshaya Rossiyskaya entsiklopediya Publ.; Drofa Publ., 1997, pp. 413-415.
5. Dubrovina K.M. Predisloviye [Preface]. Entsiklopedicheskiy slovar bibleyskikh frazeologizmov [Encyclopedic Dictionary of Bible Phraseological Units]. Moscow, Flinta Publ.; Nauka Publ., 2010, pp. 4-12.

6. Dunaev M.M. Pravoslavie i russkaya literatura: $v 5$ ch.. Ch. 1-2 [Orthodoxy and Russian Literature: In 5 parts. Parts 1-2]. Moscow, Khristianskaya lit-ra Publ., 1996. Part 1:320 p.; Part 2: 480 p.

7. Kogan L. «...Dusha moya vo mne». Ob odnom aspekte ekologii kultury [“... My Soul in me”. On One Aspect of Culture Ecology]. Sovetskaya kultura, 1986, Nov. 22

8. Kolesov V.V. «Zhizn proiskhodit ot slova...» ["Life Comes from the Word ..."]. Saint Petersburg, Zlatoust Publ., 1999. 368 p.

9. Kuraev A. (Deacon). Pochemu pravoslavnye takie? [Why Orthodox Christians such?]. Moscow, Podvorye Svyato-Troitskoy Sergievoy Lavry Publ., 2006. $528 \mathrm{p}$.

10. Losev A.F. Russkaya filosofiya [Russian philosophy]. Filosofiya. Mifologiya. Kultura [Filosofy. Mythology. Culture]. Moscow, Politizdat Publ., 1991, pp. 209-236.

11. Novitskaya Yu. Russkiy kosmizm [Russian Cosmism]. Zavtra, 2015, no. 38. Available at: http:// old.zavtra.ru/content/view/russkij-kosmizm-2/.

12. Rozenshtok-Khyussi O. Bog zastavlyaet nas govorit [God Forces Us to Speak]. Moscow, Kanon Plyus Publ., 1997. 288 p.

13. Skovorodnikov A.P. K filosofskim osnovaniyam predmetnoy oblasti ekolingvistiki [To the Philosophical Bases of Subject Domain of Ecolinguistics]. Ekologiya yazyka i kommunikativnaya praktika, 2014, no. 2, pp. 140-161.

14. Stepanov Yu.S. Konstanty. Slovar russkoy kultury. Opyt issledovaniya [Constants. Dictionary of the Russian Culture. Experience of Research]. Moscow, Yazyki russkoy kultury Publ., 1997. 824 p.

15. Trubetskoy N.S. Evropa i chelovechestvo [Europe and Mankind]. Russkiy mir: Sbornik [Russian World: Collection]. Moscow; Saint Petersburg, Eksmo Publ., Terra Fantastica Publ., 2003, pp. 663-737.

16. Fedorov N.F. Sochineniya [Compositions]. Moscow, Raritet Publ., 1994. 416 p.

\section{SOURCES AND DICTIONARIES}

Bibliya. Knigi Svyashchennogo Pisaniya Vetkhogo i Novogo Zaveta. Kanonicheskie [Bible. Books of the Scripture of the Old and New Testament]. Moscow, Bibleyskie Komissii “Dukhovnoe Prosveshchenie” Publ., 1991, vol. 2. 621 p.

Gorbachevich K.S., Khablo E.P. Slovar epitetov russkogo literaturnogo yazyka [Dictionary of Epithets of the Russian Literary Language]. Leningrad, Nauka Publ., 1979. 567 p. 
Molitvoslov [Prayer Book]. Saint Petersburg, Bibliopolis Publ., 2009. 320 p.

Natsionalnyy korpus russkogo yazyka [National Corpus of Russian Language]. Available at: http://ruscorpora/ru/.

Dyachenko G. Polnyy tserkovno-slavyanskiy slovar (s vneseniem $v$ nego vazhneyshikh drevnerusskikh slov $i$ vyrazheniy) [The Unabridged Church Slavonic Dictionary (with important Old Russian words and phrases)]. Moscow, Posad Publ., 1993. 1120 p.
Gospoda nashego Iisusa Khrista Svyatoe Evangelie ot Matfeya, Marka, Luki i Ioanna na slavyanskom i russkom yazykakh [Our Lord Jesus Christ's Sacred Gospel of Matthew, Mark, Luka and Ioann in Slavic and Russian Languages]. Saint Petersburg, Sinodalnaya tipografiya Publ., 1912. 464 p. Dubrovina K.M. Entsiklopedicheskiy slovar bibleyskikh frazeologizmov [Encyclopedic Dictionary of Bible Phraseological Units]. Moscow, Flinta Publ.; Nauka Publ., 2010. 808 p.

\section{Information About the Author}

Aleksandr P. Skovorodnikov, Doctor of Sciences (Philology), Professor-Consultant, Department of Russian Language, Literature and Speech Communication, Siberian Federal University, Prosp. Svobodnyy, 79, 660041 Krasnoyarsk, Russian Federation, skapnat@mail.ru.

\section{Информация об авторе}

Александр Петрович Сковородников, доктор филологических наук, профессор-консультант кафедры русского языка, литературы и речевой коммуникации, Сибирский федеральный университет, просп. Свободный, 79, 660041 г. Красноярск, Российская Федерация, skapnat@mail.ru. 